\title{
Effect of Water Salinity Levels on Growth Performance and Survival of Catla Catla, Genetically Improved Labeo Rohita (Jayanti Rohu) and Cirrhinus Mrigala
}

\author{
Hoque $\mathrm{F}^{1}$, Adhikari $\mathrm{S}^{1 *}$, Hussan $\mathrm{A}^{1}$, Mahanty $\mathrm{D}^{1}$, Pal $\mathrm{K}^{1}$ and Pillai BR ${ }^{2}$ \\ ${ }^{1}$ ICAR-Central Institute of Freshwater Aquaculture, Regional Research Centre- Rahara, India \\ ${ }^{2}$ ICAR-Central Institute of Freshwater Aquaculture, Kausalyaganga, India
}

*Corresponding author: Subhendu Adhikari, ICAR-Central Institute of Freshwater Aquaculture, Regional Research Centre- Rahara, Kolkata-700118, West Bengal, India, Tel: +91-9419541546; Email: subhendu66@rediffmail.com

\section{Research Article}

Volume 4 Issue 2

Received Date: June 01, 2020

Published Date: June 30, 2020

DOI: $10.23880 /$ ijoac- 16000190

\section{Abstract}

In the present work, the salinity tolerance level of Indian major carp, Catla catla, genetically improved Labeo rohita (Jayanti rohu) and Cirrhinus mrigala were ascertained in terms of weight gain and mortality by exposing the fishes gradually to different levels of salinities for 45 days. Overall analysis of the result showed that, the severity of impact of increasing salinity was significantly higher $(\mathrm{P}<0.05)$ in Catla compared to other two species (Jayanti rohu and Mrigal). In case of $C$. catla significant decrease $(\mathrm{P}<0.05)$ in weight gain was noted from 1 ppt onwards, whereas in case of $L$. rohita the decrease in weight gain was found significant $(\mathrm{P}<0.05)$ from 3 ppt onwards and in case of $C$. mrigala the growth retardation was noticed from $4 \mathrm{ppt}$ onwards compared to control. In case of Catla, mortality started at salinity above $5 \mathrm{ppt}$, and reached to $100 \%$ at salinity level of $8 \mathrm{ppt}$, whereas, Jayanti rohu showed no mortality up to $6 \mathrm{ppt}$ salinity, though the survivability got reduced to $40 \%$ in salinity of 8 ppt. Interestingly, in case of Mrigal no mortality were recorded at salinity level up to 8 ppt on 30 days post experiment. The result obtained in the present study had given an account of the level of salinity tolerance in Indian major carps.

Keywords: Salinity; Tolerance; Indian Major Carps; Weight; Survival

\section{Introduction}

Fish is considered as one of the major source of animal protein contributing $63 \%$ of the available protein in the diet. Salinity is one of the environmental factors that influence the growth performance of many fish [1]. Climate change and global warming resulted in continuous melting of glacier and sea level rise. In turn, salinity intrusion in natural fresh water sources has been reported as one of the serious problems that are exacerbated by rising sea-levels, owing to climate change, and other contributing factors, like changes in fresh water flow from rivers and increased shrimp farming along the coastal areas. Due to the increasing water salinity with the sea level rise, it impacted fish culture in ponds and other fresh water bodies especially in coastal zone. Pond water salinity also changes during periods of high precipitation or evaporation. This is pronounced in tropics where the climate is characterized by wet and dry seasons [2]. In India, though Indian Major Carps (Labeo rohita, Catla catla, Cirrhinus mrigala) comprises the dominant portion of cultured fish, but the impact of increasing salinity on growth and survival of the species needed to be investigated to meet the demand of the fishes in future with changing climate without hampering the production. Salinity is considered as a limiting factor for the survival and growth of freshwater fish species. Little work has been reported on salinity effects on growth and feed utilization of potential saline tolerant cultured fish species [3]. Although farmers in India raise fish, the potential for increasing production utilizing salinetolerant fish remains untapped. Thus the present study has been carried out to investigate the impact of salinity on the most dominant group of freshwater fishes in India i.e. Indian 
major carps.

\section{Materials and Methods}

\section{Experimental Site}

The experiment was performed at the wet lab of Regional research station- Rahara, West Bengal of Indian Council of Agricultural Research-Central Institute of Freshwater Aquaculture (ICAR-CIFA).

\section{Fish Species}

Total 200 numbers of fingerlings of Jayanti rohu (Labeo rohita), Catla (Catla Catla) and Mrigal (Cirrhinus mrigala) weighing $10.50 \pm 1.35 \mathrm{~g}$ were collected from Regional Research Centre- Rahara, ICAR-CIFA, West Bengal, India. On receipt, the fish were acclimatized separately for 15 days prior to the experiment in the fibre glass reinforced plastic tanks (FRP) of $1000 \mathrm{~L}$ capacity. The fish were fed with commercial floating feed (Growfin ${ }^{\mathrm{TM}}$ Starter feed code: 2432512 ) containing 32\% protein, $5 \%$ fat, $5.5 \%$ fibre and $11.5 \%$ moisture. Continuous aeration was provided and $30 \%$ replacement of water with fresh bore well water was done daily to avoid deposition of nitrogenous wastes.

\section{Experimental Design}

The salinity $(0,1,2,3,4,5,6,7$ and $8 \mathrm{ppt})$ was maintained by mixing desired levels of commercial sodium chloride $(\mathrm{NaCl})$ to freshwater. Total 10 numbers of the acclimatized fingerlings were subjected to each of the salinity regimes of $0,1,2,3,4,5,6,7$ and 8 ppt in FRP tanks containing $200 \mathrm{~L}$ water in triplicates. Sodium chloride $(\mathrm{NaCl})$ was used in this study instead of seawater due to theirfrequent use to raise salinity during husbandry practices of these species [4]. The salinity level was measured using Labman Multi-parameter water quality meter LMMP-30, India. The water parameters were examined on the initial day of the experimentation and on weekly interval till the final day of sampling.The fish were raised in their respective tanks for 45 days. Sampling was done on $0 \mathrm{~d}, 15 \mathrm{~d}, 30 \mathrm{~d}$ and $45 \mathrm{~d}$ of the experiment, which included recording survival rate (\%) and weight gain of fish (gm).

\section{Data Analysis}

The survival percentage was recorded (No of fishes survived after 45 days/Initial no. of fishes stockedx 100). Data were expressed as mean \pm standard deviation. The data were analyzed by analysis of variance (ANOVA) [5]. Statistical software SPSS version 16.0 was used to analyse data with the levels of significance at $\mathrm{P}<0.05$.

\section{Results}

\section{Growth and Survivability of IMC under different Salinity Levels}

Overall analysis of the result showed that, the severity of impact of increasing salinity was significantly higher $(\mathrm{P}<0.05)$ in Catla compared to other two species (Jayanti rohu and Mrigal). In case of $C$. catla significant decrease $(\mathrm{P}<0.05)$ in weight gain was noted from 1 ppt onwards (Figure 2), whereas in case of $L$. rohita the decrease in weight gain was found significant $(\mathrm{P}<0.05)$ from 3 ppt onwards (Figure 1 ) and in case of $C$. mrigala the growth retardation was noticed from 4 ppt onwards compared to control (Figure 3 ). In case of Catla, mortality started at salinity above 5 ppt, and reached to $100 \%$ at salinity level of 8 ppt (Figure 5). In case of Jayanti rohu no mortality was recorded up to 6 ppt salinity, though the survivability got reduced to $40 \%$ in salinity of 8 ppt (Figure 4). Interestingly, in case of Mrigal no mortality were recorded at salinity level up to $8 \mathrm{pp}$ ton 30 days post experiment (Figure 6). In case of all the species weight gain was found decreased with increase in salinity. In case of Jayanti rohu, reduction in weight gain was not significantly different $(\mathrm{P}>0.05)$ from control up to $2 \mathrm{ppt}$ level and then it reduced at a rate of around $10 \%$ with each ppt of salinity increase up to 6ppt salinity; but in case of Catla reduction in weight gain with increased salinity was found inconsistent and even at 2 ppt salinity average weight gain reduced to nearly $50 \%$ compared to control $(0 \mathrm{ppt})$. But in case of Mrigal, no significant difference $(P>0.05)$ in weight gain was found up to 3 ppt salinity. Overall analysis of the result showed that, the severity of impact of increasing salinity was significantly higher $(\mathrm{P}<0.05)$ in Catla compared to other two species (Jayanti rohu and mrigal). In case of $C$. catla significant decrease $(\mathrm{P}<0.05)$ in weight gain was noted from 1 ppt onwards, whereas in case of $L$. rohita from $3 \mathrm{ppt}$ and in case of $C$. mrigala from 4 ppt onwards compared to control.

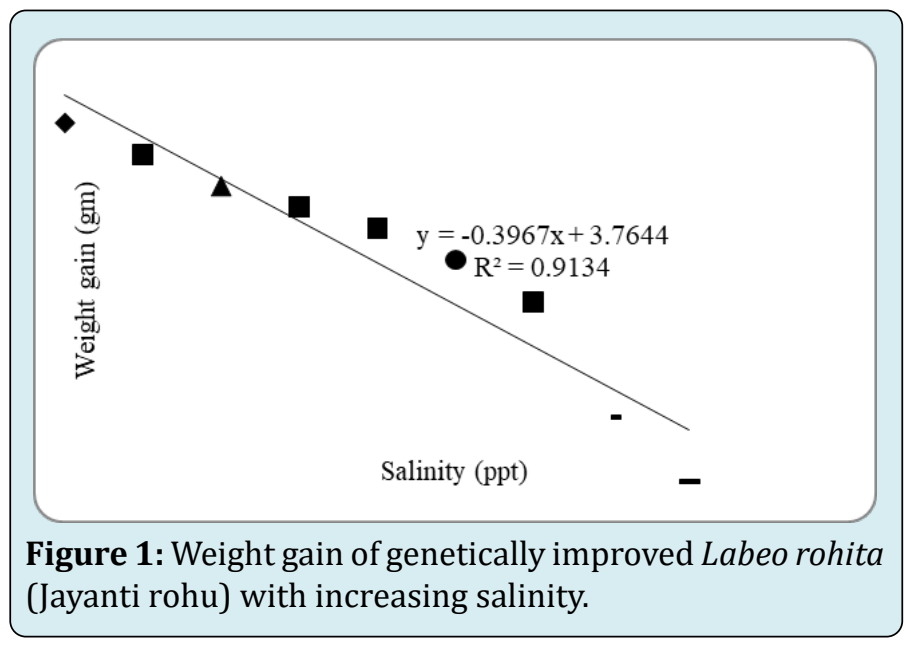



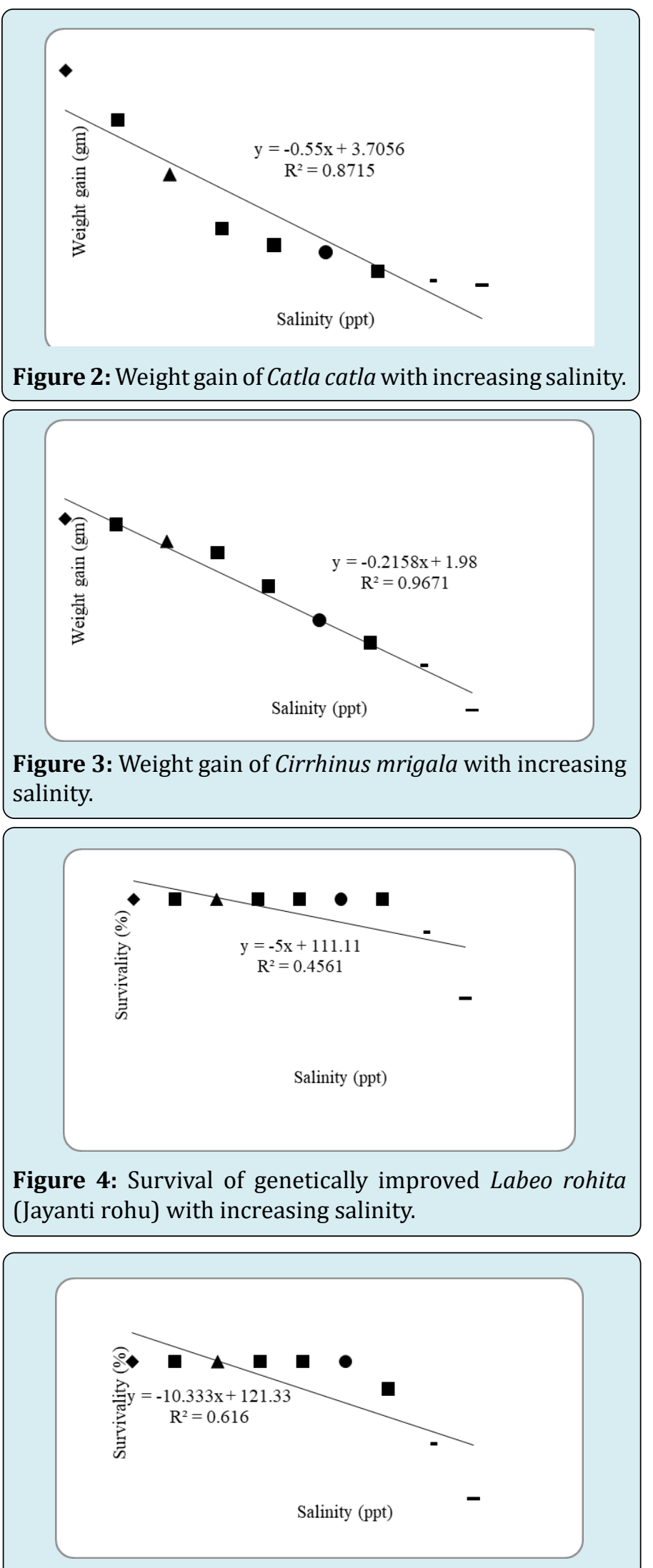

Figure 5: Survival of Catla catla with increasing salinity.

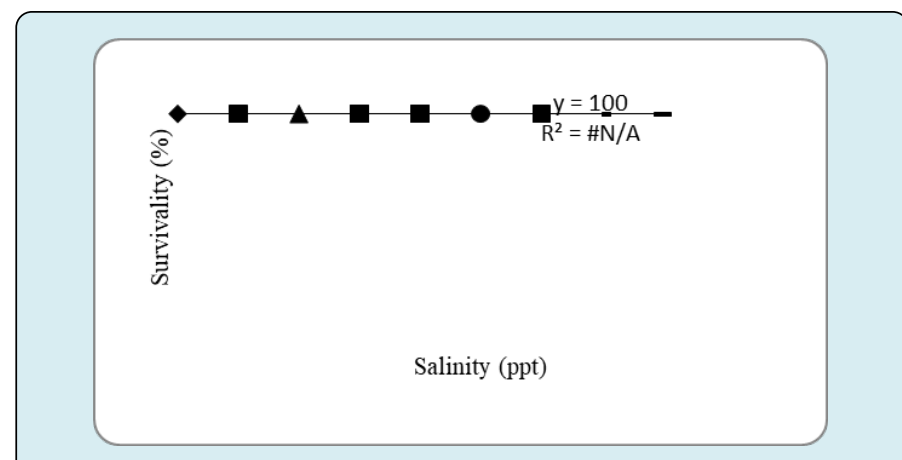

Figure 6: Survival of Cirrhinus mrigala with increasing salinity.

\section{Discussion}

Every fish species has different optimum salinity ranges for growth and survival. With fluctuations in environmental salinity, morphological, biochemical and endocrinological alterations have been evidenced in fish leading to increasing demand of energy [6]. Growth and survival to changes in salinity may provide a bio-energetic basis to evaluate performance of fish under different culture conditions. This is also relevant for the culture of salinity-tolerant aquaculture candidates which could be reared at different salinities. In the present study, significant decrease in weight gain was reported in $C$. catla $(\mathrm{P}<0.05)$ from 1 ppt onwards, whereas in case of $L$. rohita the decrease in weight gain was found significant $(\mathrm{P}<0.05)$ from 3 ppt onwards and in case of $C$. mrigala the growth retardation was noticed from $4 \mathrm{ppt}$ onwards compared to control. Recent studies demonstrated that salinity change can induce stress in aquatic animals by interfering with physiological homeostasis, routine biological processes and accelerating oxidative damage [7], resulting in decrease in weight gain. This study reported that in case of Catla, mortality started at salinity above $5 \mathrm{ppt}$, and reached to $100 \%$ at salinity level of 8 ppt. In case of Jayanti rohu the survival of fish got reduced to $40 \%$ in salinity of 8 ppt. Interestingly, in case of Mrigal no mortality were recorded at salinity level up to 8 ppt on 30 days post experiment. Fiúza, et al. [8] reported that salinity higher than 5 ppt has significant effects on the growth, survival, haematological parameters and osmoregulation of tambaqui (Colossoma macropomu) juveniles. James, et al. [9] studied that the maximum salinity tolerance was $11 \mathrm{ppt}$ for channel cat fish, $12 \mathrm{ppt}$ for blue cat fish and 13 ppt for white cat fish. Ghosh, et al. [10] observed that common carp can be profitably cultured up to $5 \mathrm{ppt}$ salinity and there was no adverse effect on the fish even when the salinity was raised to 7 ppt. Mohammadi, et al. [11] revealed that brood fish of Rainbow Trout, Oncorhynchus mykiss that were reared for 6 months in underground brackish water (11 ppt) successfully matured and spawned and their gonad quality was better than the broodfish in freshwater. 
The earlier studies indicated that juveniles of rohu could grow upto 4 ppt salinity level, but less growth was observed as salinity increased above 4 ppt [12]. Based on the present investigation, we recommend culturing Mrigal in salinity upto 8 ppt without hampering the production, whereas Catla was found to be least tolerant to salinity fluctuations. The improved rohu Jayanti was found to grow significantly at salinity upto 3 ppt. Contrarily, Murmu, et al. [6] reported that Jayanti rohu can be cultured in salt affected areas upto 8 ppt and there is great potential to incorporate this species in low saline aquaculture. However, this comprehensive study serves as the basis to sustain the aquaculture production in the climate change scenarios with reference to saline zone and useful in preparation of management plan for carp culture, where water salinity varies within the study level.

\section{Acknowledgement}

The funding of NICRA (National Innovation on Climate Resilient Agriculture) for conducting of the present investigation is gratefully acknowledged. The authors are also thankful to the Director, ICAR-CIFA for providing research facilities at the Institute.

\section{References}

1. Watanabe W, Olla BL, Wiklund RI, Head WD (1997) Saltwater culture of the Florida red tilapia and other saline-tolerant tilapias: A review. In: Costa-Pierce BA, Rokocy JE, (Eds.), Tilapia aquaculture in Americas, World Aquaculture Society, Baton Rouge, LA 1: 54-141.

2. Boyd CE, Tucker CS (1998) Pond Aquaculture Water Quality Management. Kluwer Academic Publishers, London, pp: 700.

3. Likongwe JS (2002) Studies on potential use of salinity to increase growth of tilapia in aquaculture in Malawi. In: McElwee K, Lewis K, Nidiffer M, Buitrago P, (Eds.), Nineteenth Annual Technical Report. Pond Dynamics/ Aquaculture CRSP, Oregon State University, Corvallis, OR, pp: $167-174$.
4. Tsuzuki MY, Aikawa H, Strüssmann CA, Takashima F (2000) Physiological responses to salinity increases in the freshwater silversides Odontesthes bonariensis and O. hatcheri (Pisces, Atherinidae). Rev Bras Oceanogr 48(1): 81-85.

5. Weissgerber TL, Garcia-Valencia O, Garovic VD, Milic NM, Winham SJ (2018) Why we need to report more than 'Data were Analyzed by t-tests or ANOVA'. eLife 7: e36163.

6. Murmu K, Rasal KD, Rasal A, Sahoo L, Nandanpawar PC, et al. (2019). Effect of salinity on survival, hematological and histological changes in genetically improved rohu (Jayanti), Labeo rohita (Hamilton, 1822). Indian Journal of Animal Research, pp: B-3801.

7. Kultz D (2015) Physiological mechanisms used by fish to cope with salinity stress. Journal Experimental Biology 218: 1907-1914.

8. Fiúza LS, Aragão NM, Junior R, Pinto H, Moraes MG, et al. (2015) Effects of salinity on the growth, survival, haematological parameters and osmoregulation of tambaqui Colossoma macropomum juveniles. Aquaculture Research 46(1): 1-9.

9. James KR, Cant B, Ryan T (2003) Responses of freshwater biota to rising salinity levels and implications for saline water management: a review. Australian Journal Botany 51: 703-713.

10. Ghosh AN, Ghosh SR, Sarkar NN (1973) On the salinity tolerance of fry and fingerlings of Indian major carps. Journal of Inland Fisheries Society India 5: 215-217.

11. Mohammadi M, Sarsangi H, Askari M, Bitaraf A, Mashaii $\mathrm{N}$, et al. (2011) Use of underground brackish water for reproduction and larviculture of Rainbow Trout, Oncorhynchus mykiss. Journal of Applied Aquaculture 23(2): 103-111.

12. Baliarsingh MM, Panigrahi JK, Patra AK (2018) Effect of salinity on growth and survivality of Labeorohita in captivity. International J Scientific Res 7(4): 28-30. 